\title{
UM BREVE COMENTÁRIO A RESPEITO DO IPCC AR6
}

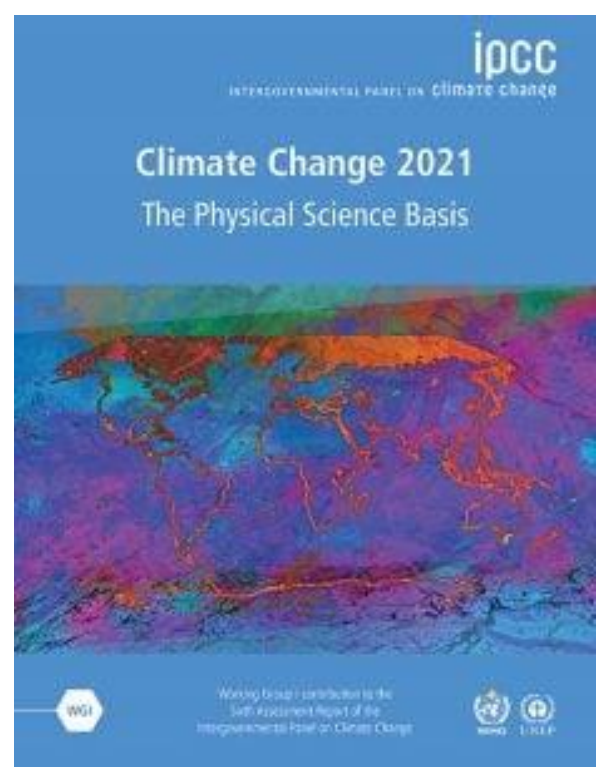

\section{Vinícius Machado Rocha}

Doutor. Professor da Universidade Federal do Recôncavo da Bahia (UFRB)

E-mail: vinimrocha@ufrb.edu.br

As mudanças climáticas atuais são reais, causadas pelas atividades antropogênicas, estão se intensificando numa velocidade surpreendente, sem precedentes nos últimos 2 mil anos. Suas consequências mostram-se potencialmente gravíssimas para os seres humanos e para a Terra, incluindo a intensificação de tempestades, secas severas e ondas de calor extremo. A frequência e intensidade dos eventos climáticos extremos aumentaram na maioria das áreas continentais desde 1950 e irão se agravar nas próximas décadas proporcionalmente ao aquecimento global. Se a temperatura média do planeta aumentar 4,0 ${ }^{\circ} \mathrm{C}$ (em relação ao período de 1850-1900) antes de 2100 o número de eventos climáticos extremos em algumas regiões pode se tornar nove vezes maior (IPCC AR6, 2021).

O alerta foi feito pelo Sexto Relatório de Avaliação (AR6, em inglês) do Painel Intergovernamental sobre Mudanças Climáticas (IPCC), divulgado no mês de agosto de 2021 em Genebra, na Suíça, reunindo as principais conclusões da contribuição do Grupo de Trabalho 1 (GT1) do órgão. A publicação sintetiza o conhecimento sobre as bases físicas das ciências relacionadas ao clima. Em outras palavras, o relatório produzido pelo GT1 analisa as evidências científicas da mudança do clima. 
Mais de 14 mil estudos foram analisados na elaboração do AR6 e as evidências não deixam dúvidas nem sobre o papel do homem na mudança do clima global, nem sobre a gravidade do problema. O que muda nesse novo documento em relação ao Quinto Relatório de Avaliação (AR5) publicado em 2013 (IPCC AR5, 2013) é, principalmente, o grau de refinamento das análises sobre o que está ocorrendo e das projeções sobre o que pode vir a acontecer no futuro, com base nos novos conhecimentos acumulados ao longo dos últimos oito anos.

De acordo com o Sumário para Tomadores de Decisão (Summary for Policy Makers), é inequívoco que a ação humana, por meio da emissão de gases de efeito estufa (GEE) originados principalmente pela queima de combustíveis fósseis para geração de energia e, especialmente no Brasil, por mudanças no uso e cobertura da terra (desflorestamento), aqueceu o sistema climático e que estão ocorrendo mudanças generalizadas, rápidas e irreversíveis (IPCC AR6, 2021). Comparativamente, o IPCC AR5 (2013) reportava ser "extremamente provável" que a influência humana fosse a causa preponderante do aquecimento observado desde meados do século XX”. Portanto, ao empregar o termo "inequívoco" o IPCC AR6 (2021) acrescenta mais certeza e contundência ao fato. A mudança climática induzida pelo homem já está afetando muitos extremos climáticos e meteorológicos em todas as regiões do globo (IPCC AR6 2021).

De acordo com o Atlas da Mortalidade e Perdas Econômicas por Extremos Meteorológicos, Climáticos e Hídricos (Atlas of Mortality and Economic Losses from Weather, Climate and Water Extremes), divulgado pela Organização Meteorológica Mundial (OMM) também no mês de agosto de 2021, as mudanças climáticas e os eventos extremos quintuplicaram o número de desastres naturais em 50 anos. Foram reportados mais de 11 mil desastres de 1970 a 2019, com pouco mais de 2 milhões de mortes e US\$ 3,64 trilhões em danos. De modo geral, o documento afirma que as perdas econômicas aumentaram sete vezes nas cinco décadas (de uma média diária de US\$ 49 milhões na década de 1970 para US\$ 383 milhões no período 2010-2019), mas o número de mortes diminuiu quase três vezes no mesmo período (de mais de 50 mil por ano na década de 1970 para menos de 20 mil na década de 2010), em razão de alertas precoces e gerenciamento aprimorado. No entanto, isso ocorreu de maneira desigual no planeta: mais de $91 \%$ das mortes se concentraram em países em desenvolvimento. Também é verdade 
que o número de pessoas expostas a risco de desastre aumentou devido ao crescimento populacional em áreas expostas a perigos e à crescente intensidade e frequência de eventos climáticos. Os desastres climáticos representaram metade de todos os desastres, concentrando $45 \%$ de todas as mortes reportadas e $74 \%$ de todas as perdas econômicas no período. Dos 10 principais tipos de desastres documentados, as secas foram as mais mortais (650 mil mortes). Tempestades causaram 577,2 mil mortes, seguidas de inundações (58,7 mil mortes) e eventos de temperaturas extremas (55,7 mil mortes). $\mathrm{Na}$ América do Sul, as enchentes causaram o maior número de desastres (59\%), a maior perda de vidas (77\%) e a maior perda econômica (58\%) no período de 50 anos analisado (WMO, 2021).

Portanto, não é apenas o clima médio que está mudando, mas também os extremos climáticos. De modo geral, quanto maior o aquecimento, maior a frequência e intensidade de eventos extremos, e maior a probabilidade de eventos que hoje são raros se tornarem relativamente comuns.

Um ou dois graus celsius a mais de temperatura altera profundamente $o$ funcionamento do sistema climático terrestre como um todo. Na verdade, cada meio grau $\left(0,5^{\circ} \mathrm{C}\right)$ faz uma diferença muito grande em termos de impactos. As consequências práticas, segundo o IPCC AR6 (2021), são: aumento na ocorrência e intensidade de tempestades, secas, ondas de calor e outros eventos climáticos extremos; derretimento acelerado de geleiras e da calota polar do Ártico; aumento do nível e da temperatura do mar; mudanças drásticas nos padrões de precipitação ao redor do mundo; entre outras. Eventos de seca que, antes da interferência humana no clima, só ocorriam uma vez a cada dez anos poderão ocorrer duas a três vezes no mesmo período num planeta $2,0^{\circ} \mathrm{C}$ mais quente. Eventos de calor extremo que só ocorriam uma vez a cada 50 anos poderão ocorrer 14 vezes no mesmo período de tempo. Como é evidente se observar, a produção de alimentos, a segurança hídrica, a conservação da biodiversidade, a qualidade de vida nas cidades, a saúde, a produção de energia e inúmeras outras atividades essenciais à sobrevivência dos seres humanos na Terra experimentariam implicações consideráveis.

Atualmente, segundo o IPCC AR6 (2021) a temperatura média global está em torno de $1,1^{\circ} \mathrm{C}$ em relação à média observada entre 1850 e 1900 , utilizada como referência de temperatura normal do planeta, ou seja, antes do início da interferência humana no 
clima, e continua subindo. Na verdade, em áreas continentais o aumento da temperatura já está em $1,6^{\circ} \mathrm{C}$, comparado a $0,9^{\circ} \mathrm{C}$ nos oceanos (o que dá uma média de $1,1^{\circ} \mathrm{C}$ de aquecimento global total, comparado à era pré-industrial).

Em escala global, porém, esse limite só não foi superado ainda, por causa de um outro problema gerado pelo homem: a poluição do ar urbana, que contém partículas (aerossóis e fuligem) que refletem a energia solar de volta ao espaço e, dessa forma, produzem um efeito de resfriamento - oposto ao causado pelos GEE. De acordo com o IPCC AR6 (2021), essa poluição reduziu o aquecimento global até agora em $0,5^{\circ} \mathrm{C}$. Em outras palavras, o material particulado presente na atmosfera está mascarando cerca de um terço do aquecimento que já ocorreu.

Nos últimos 50 anos a temperatura da superfície global aumentou a uma taxa sem precedentes e é muito provável que a década mais recente tenha sido a mais quente dos últimos 125 mil anos. É inequívoco, também, que o aquecimento observado foi impulsionado pelo aumento da concentração de GEE na atmosfera, principalmente o dióxido de carbono $\left(\mathrm{CO}_{2}\right)$ que em 2019 atingiu 410 partes por milhão (ppm) - a concentração mais alta nos últimos 2 milhões de anos, segundo o IPCC AR6 (2021).

O IPCC AR6 (2021) utilizou cinco novos cenários de emissões de GEE (identificados pela sigla SSPs - The Shared Socio Economic Pathways) para o período de 2015 a 2100 e modelos climáticos mais sofisticados nas simulações numéricas. Dessa maneira, foi possível preencher algumas lacunas de dados e promover uma maior integração das evidências. Como resultado, o IPCC AR6 (2021) traz projeções mais apuradas do impacto das emissões de GEE no sistema climático terrestre.

No cenário mais otimista (SSP1-1.9), as emissões antrópicas de dióxido de carbono decairiam rapidamente nas próximas décadas, chegando a emissões líquidas zero por volta de 2050, e tornando-se negativas a partir daí - o que exigiria não somente a redução de emissões, mas também a implementação de medidas capazes de remover o excesso de carbono já acumulado na atmosfera, como o plantio de árvores em larga escala por todo o planeta; ou seja, a sociedade removeria mais carbono da atmosfera do que acrescenta.

No segundo cenário otimista (SSP1-2.6), isso também ocorreria, porém, a partir de 2080. No cenário intermediário (SSP2-4.5), as emissões de certo modo ainda 
aumentariam nos próximos anos e reduziriam em meados do século XXI, mas não o suficiente para chegar a zero antes de 2100. Já nos dois cenários mais pessimistas (SSP37.0 e SSP5-8.5) as emissões continuariam aumentando nas próximas décadas, contudo, em intensidades distintas.

Em todos os períodos considerados (curto prazo: 2021-2040; médio prazo: 2041-2060; e longo prazo: 2081-2100), na melhor estimativa do IPCC AR6 (2021), o aquecimento atingiria ou ultrapassaria a marca de $1,5^{\circ} \mathrm{C}$ nos próximos 20 anos, a não ser que houvesse uma ação imediata e contundente da sociedade no sentido de mudar essa trajetória. O cenário que melhor representa a trajetória atual da Terra é o SSP3-7.0, no qual o aquecimento global ultrapassaria $2,0^{\circ} \mathrm{C}$ por volta de 2050 e chegaria a $3,6^{\circ} \mathrm{C}$ no fim do século, com potencial para chegar a $4,6^{\circ} \mathrm{C}$, o que implicaria mudanças climáticas extremas e potencialmente catastróficas para os seres humanos e todos os ecossistemas do planeta.

Uma das consequências mais impactantes e irreversíveis do aquecimento global é a elevação do nível do mar, causada pela sinergia entre aumento da temperatura da água (que aumenta o volume dos oceanos, por um processo físico de expansão térmica) e derretimento em massa de geleiras, tanto em terra quanto nos oceanos.

De acordo com o IPCC AR6 (2021), o nível global do mar aumentou $20 \mathrm{~cm}$ entre 1901 e 2018, e é muito provável (90\% a 100\% de probabilidade) que esse aumento seja resultado do aquecimento global causado pelo homem, principalmente nos últimos 50 anos.

A velocidade com que essa elevação está ocorrendo é sem precedentes nos últimos 3 mil anos; e mesmo que as emissões de GEE zerassem imediatamente, essa elevação continuará em curso por pelo menos mais alguns séculos ou milênios, em função do tempo que o calor leva para ser absorvido e se dissipar no oceano. Ainda de acordo com o relatório, estima-se que o nível do mar subirá de $2 \mathrm{~m}$ a $3 \mathrm{~m}$ nos próximos 2 mil anos, se o aquecimento global for limitado a $1,5^{\circ} \mathrm{C}$; ou até $6 \mathrm{~m}$, num cenário de $2^{\circ} \mathrm{C}$.

No cenário intermediário (SSP2-4.5), projeta-se o aumento no nível global do mar em torno de 44 a $76 \mathrm{~cm}$ até 2100. É uma mudança expressiva, que, combinada com o aumento do número e da intensidade de chuvas e tempestades, pode gerar graves 
implicações sobre as zonas costeiras continentais, onde vive a maior parte da população brasileira.

O IPCC AR6 (2021) prevê, também, que as geleiras continentais e os mantos de gelo polar continuarão a derreter por centenas de anos, assim como o solo congelado (permafrost) da Sibéria, que contém uma quantidade enorme de metano $\left(\mathrm{CH}_{4}\right)$ armazenado. O Ártico está se aquecendo duas vezes mais rápido do que o restante do planeta, e a cobertura de gelo marinho durante o verão tem diminuído significativamente nas últimas décadas.

Outros efeitos irreversíveis nos próximos séculos incluem o aquecimento, a acidificação e a desoxigenação das águas oceânicas, com impactos significativos para a biodiversidade marinha global. Ainda que não seja possível frear completamente os processos em curso, o relatório ressalta que a diminuição das emissões de GEE e, consequentemente, do aquecimento global pode reduzir consideravelmente a magnitude e duração dos impactos a médio e longo prazo.

Em escala global, os eventos de chuva forte se intensificarão em cerca de 7\% para cada grau adicional de aquecimento, uma vez que a atmosfera aquecida é capaz de reter mais umidade (IPCC AR6, 2021).

Contudo, as simulações numéricas indicam que a região norte da América do Sul se tornará gradativamente mais quente e seca à medida que a temperatura global aumenta, o que poderá alterar gravemente o equilíbrio ecossistêmico da Amazônia como um todo. O mesmo aconteceria na região Nordeste do Brasil, que já é naturalmente seca, o que acarretaria impactos importantes para a segurança hídrica, energética e alimentar da região.

A região central da América do Sul, onde está concentrada a maior parte do agronegócio brasileiro, deverá registrar maior aumento na temperatura e elevação da frequência e intensidade das ondas de calor, além de períodos secos mais prolongados. $\mathrm{O}$ Sudeste do Brasil se tornaria, além de mais quente, susceptível a mais extremos climáticos de natureza hídrica.

Por outro lado, na região Sul do Brasil devem ocorrer mais chuvas fortes e com grandes volumes de água. Na verdade, na região mais ao sul do Brasil já se observa um aumento das precipitações. 
Em um cenário de aquecimento global de $2,0^{\circ} \mathrm{C}$, a temperatura no Brasil pode aumentar, em média, entre $3,0^{\circ} \mathrm{C}$ e $3,5^{\circ} \mathrm{C}$. No entanto, se a temperatura média global aumentar em $4,0^{\circ} \mathrm{C}$, projeta-se para o Brasil um aquecimento entre $5,0^{\circ} \mathrm{C}$ e $5,5^{\circ} \mathrm{C}$, principalmente na porção central do país. Isso desencadearia sérios prejuízos à saúde da população, graves consequências aos biomas brasileiros (como o aumento das queimadas) e implicações importantes para a economia do país, incluindo a produção agrícola. $\mathrm{Na}$ verdade, cada $0,5^{\circ} \mathrm{C}$ adicional de aquecimento global causará aumentos estatisticamente significativos nos extremos de temperatura, na intensidade de tempestades e na gravidade de secas em algumas regiões, como no Nordeste do Brasil e no leste da Amazônia.

Uma mudança que chama a atenção no IPCC AR6 (2021) é o recálculo da quantidade de carbono já emitida pelas atividades antrópicas e o encurtamento da janela de tempo dentro da qual o aquecimento global ultrapassará a marca de $1,5^{\circ} \mathrm{C}$ acima da temperatura "normal" da era pré-industrial. De acordo com o relatório, as atividades antropogênicas emitiram à atmosfera 2.390 bilhões de toneladas de dióxido de carbono entre 1850 e 2019, sendo que a maior parte dessas emissões (entre $80 \%$ e 90\%) foi gerada pela queima de combustíveis fósseis (petróleo, gás e carvão mineral).

Para limitar o aquecimento global a $1,5^{\circ} \mathrm{C}$ é necessário, portanto, que as emissões de $\mathrm{CO}_{2}$ não ultrapassem o valor de 2.900 bilhões de toneladas. No ritmo atual de 40 bilhões de toneladas emitidas por ano, o limite seria superado por volta de 2040.

O objetivo do Acordo de Paris, firmado em 2015 com base nas conclusões do IPCC AR5 (2013), é justamente manter o aquecimento global bem abaixo de $2,0^{\circ} \mathrm{C}$ e, preferencialmente, até um limite máximo de $1,5^{\circ} \mathrm{C}$.

A temperatura média global da superfície continuará a aumentar até pelo menos meados deste século em todos os cenários de emissões considerados. As taxas de aquecimento global de $1,5^{\circ} \mathrm{C}$ e $2,0^{\circ} \mathrm{C}$ serão excedidas durante o século XXI, a não ser que reduções significativas nas emissões de $\mathrm{CO}_{2}$ e outros $\mathrm{GEE}$ ocorram nas próximas décadas (IPCC AR6, 2021).

A escala das mudanças recentes no sistema climático como um todo e o estado atual de muitos aspectos do sistema climático não têm precedentes num período de muitos séculos a muitos milhares de anos. A mensagem do IPCC AR6 (2021) é clara: mudar 
agora e preparar-se para o impacto. Os pontos de ruptura estão se aproximando e o único nível aceitável de emissões é zero.

Sem uma reação imediata em grande escala, ou seja, de todos os países, no sentido de reduzir significativamente as emissões de GEE, a meta de limitar o aquecimento global a $1,5^{\circ} \mathrm{C}$ pode se tornar impossível. As emissões globais de $\mathrm{CO}_{2}$ teriam de ser reduzidas cerca de 7\% ao ano até 2050. A solução está posta. O IPCC AR6 (2021) demonstra claramente o que deve ser realizado.

O novo ciclo de avaliação do Painel Intergovernamental sobre Mudanças Climáticas (IPCC) deverá ser concluído no início de 2022, quando será publicado o relatório com as contribuições do Grupo de Trabalho 2, com foco em impactos, adaptação e vulnerabilidade às mudanças climáticas, e do Grupo de Trabalho 3, com enfoque em mitigação. A expectativa é que os relatórios embasem as negociações climáticas dos países nas próximas conferências da Organização das Nações Unidas (ONU) sobre o clima (COPs).

\section{REFERÊNCIAS}

IPCC AR5 (Intergovernmental Panel on Climate Change). Summary for Policymakers. In: STOCKER, T.F.; QIN, D.; PLATTNER, G.K.; TIGNOR, M.; ALLEN, S.K.; BOSCHUNG, J.; NAUELS, A.; XIA, Y.; BEX, V.; MIDGLEY, P.M. (Eds). Climate Change 2013: The Physical Science Basis. Contribution of Working Group I to the Fifth Assessment Report of the Intergovernmental Panel on Climate Change. Cambridge, U.K. and New York, USA: Cambridge University Press, 2013, 27 pp.

IPCC AR6 (Intergovernmental Panel on Climate Change). Summary for Policymakers. In: MASSON-DELMOTTE, V., P. ZHAI, A. PIRANI, S. L. CONNORS, C. PÉAN, S. BERGER, N. CAUD, Y. CHEN, L. GOLDFARB, M. I. GOMIS, M. HUANG, K. LEITZELL, E. LONNOY, J.B.R. MATTHEWS, T. K. MAYCOCK, T. WATERFIELD, O. YELEKÇI, R. YU AND B. ZHOU (Eds). Climate Change 2021: The Physical Science Basis. Contribution of Working Group I to the Sixth Assessment Report of the Intergovernmental Panel on Climate Change. Cambridge University Press, 2021, 41 pp.

WMO, 2021: The Atlas of Mortality and Economic Losses from Weather, Climate and Water Extremes.

<https://library.wmo.int/index.php?lvl=notice_display\&id=21930\#.YT_XuxmSIPZ> Acesso em: 20 de set. 2021.

Recebido em setembro de 2021.

Revisão realizada em outubro de 2021. 